\title{
REVIEWS
}

\section{The Production of Propene Oxide: Catalytic Processes and Recent Developments}

\author{
T. Alexander Nijhuis, ${ }^{*, \dagger}$ Michiel Makkee, ${ }^{\ddagger}$ Jacob A. Moulijn,,$\stackrel{\dagger}{ }$ and Bert M. Weckhuysen ${ }^{\dagger}$ \\ Department for Inorganic Chemistry and Catalysis, Faculty of Science, Utrecht University, Sorbonnelaan 16, \\ 3584 CA Utrecht, The Netherlands, and Department for Reactor and Catalysis Engineering, Faculty of Applied \\ Sciences, Delft University of Technology, Julianalaan 136, 2628 BL Delft, The Netherlands
}

Propene oxide, which is one of the major commodity chemicals used in chemical industry, desperately requires a new process for its production, because of the disadvantages that are encountered with the currently available processes. This paper discusses the existing processes used for the production of propene oxide-the chlorohydrin and hydroperoxide processes - and their advantages and disadvantages. Furthermore, the new processes and catalysts under development for the propene oxide production are discussed, as well as the challenges that are still limiting the applications of some of those prospects. The most important new developments for the production of propene oxide discussed in this paper are: the hydrogen peroxide combination process, the ethene oxide alike silver catalysts, the molten salt systems, and the gold-titania catalyst systems.

\section{Introduction}

Propene oxide, which is also known as propylene oxide, methyloxirane, or 1,2-epoxypropane, is one of the most important starting materials in the chemical industry. The production of propene oxide consumes over $10 \%$ of all propene produced. ${ }^{1,2}$ In 1999, the total production for propene oxide amounted to $\sim 5.8$ million tons per year. ${ }^{3}$ This market is annually growing by $\sim 4 \%-5 \%$. 1,3 The major application of propene oxide is in the production of polyether polyols $(65 \%)$, which are mainly used for the production of (polyurethane) foams. The second and third largest applications are in the production of propene glycol $(30 \%)$ and propene glycol ethers $(4 \%)$, respectively. ${ }^{4}$ Propene glycols are mainly used in the production of polyesters, whereas propene glycol ethers are primarily used as solvents.

Propene oxide is currently produced using two different types of commercial processes: the chlorohydrin process and the hydroperoxide process. In 1999, the production capacity was distributed evenly between these two processes; however, because of the environmental impacts of the chlorohydrin process, the most recently built plants are all using hydroperoxide process technologies. However, a disadvantage of the hydroperoxide processes is the production, in a fixed ratio, of a coproduct (either styrene or tert-butyl alcohol, depending on which variant of the hydroperoxide process is applied). Because these co-products are produced in a volume that is $\sim 3$ times larger than that of propene oxide, the economy of the process is primarily dominated by the market of the co-product. A major research effort has been made in the development of alternative direct epoxidation processes for the production of propene oxide. The aim has been to develop a process for the direct gas-phase oxidation, similar to the direct epoxidation of ethene. However, the selectivity of the catalysts that have been developed for the direct epoxidation using oxygen or air is, by far, insufficient to

* To whom correspondence should be addressed. Phone: +31-302537763. Fax: +31-30-2511027. E-mail: x.nijhuis@chem.uu.nl.

Utrecht University.

$\doteqdot$ Delft University of Technology. result in a viable process (usually $<30 \%$, with the remaining portion of the propene being converted to carbon dioxide). Olin developed a process for the direct epoxidation of propene using molten salt "catalysis", claiming promising results of $65 \%$ selectivity to propene oxide at $15 \%$ propene conversion. ${ }^{5}$ However, this process is not yet commercially applied. An alternative to using alkyl-hydroperoxides, which are used in dehydroperoxide processes, is hydrogen peroxide. Especially, when TS-1 (titanium silicalite-1) is used as a catalyst, this allows for the possibility of a very selective (95\%) and hydrogen peroxide-efficient production of propene oxide. ${ }^{6}$ However, the major problem for the commercialization of this process is the fact that, on a molar basis, propene oxide and hydrogen peroxide have comparable market values, making it impossible to run the process profitably at this time. For other epoxides used in fine chemistry, the use of hydrogen peroxide or organic peroxides is more favorable, because the cost of these oxidants is much smaller, compared to the product value. The disadvantage of the high cost of hydrogen peroxide for the propene epoxidation can be solved by the in situ production of the hydrogen peroxide, which is a process that is currently under construction by Dow-BASF. ${ }^{7}$

Another route toward the production of propene oxide under development is based on propene epoxidation, using a mixture of hydrogen and oxygen over a gold-titania catalyst. After Haruta and co-workers ${ }^{8}$ discovered this system almost a decade ago, many research groups performed work on this catalyst. Although the selectivity for propene oxide is very high, the low conversion and hydrogen efficiency still need to be improved. Also, the mode of operation of the catalyst is still unclear.

This paper will discuss the aforementioned propene epoxidation processes that are in use and those under development, and the paper examines the possibilities for alternative epoxidation routes.

\section{Current Processes}

1. Chlorohydrin Process. The synthesis of ethane oxide and propene oxide using the chlorohydrin route was first described 


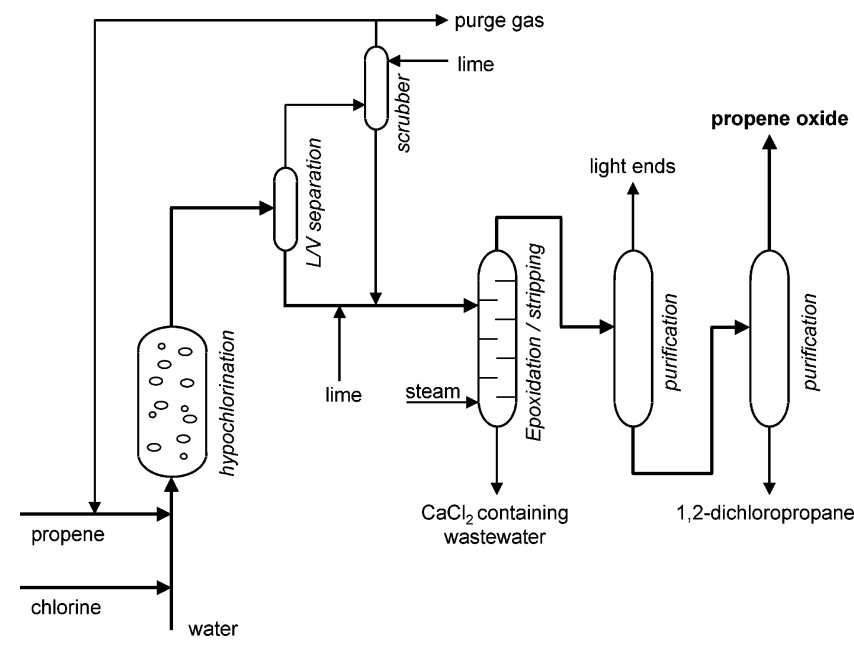

Figure 1. Schematic representation of the chlorohydrin process for the production of propene oxide.

in 1859 by Wurtz. ${ }^{9}$ In this reaction, the alkene reacts with hypochlorous acid $(\mathrm{HOCl})$ to produce the chlorohydrin. The hypochlorous acid is produced in situ by an equilibrium reaction of the acid with water and chlorine. The chlorohydrin is thereafter dehydrochlorinated, using aqueous potassium hydroxide to produce the epoxide. ${ }^{10}$ The conversion of chlorohydrins to epoxides is performed by an adaptation of the Wilkinson synthesis for ethers. ${ }^{11}$ This route has long been the main process for producing both ethene oxide and propene oxide. In the 1940 s, the process began to be phased out for the ethene epoxidation, because of the development of a more-efficient direct epoxidation process using a silver catalyst. After that introduction, many ethene epoxidation plants that were using the chlorohydrin process were converted for the epoxidation of propene. The process is still applied for the propene epoxidation; however, at the moment, it is gradually being replaced by the more environmentally friendly hydroperoxide processes.

Figure 1 schematically demonstrates the chlorohydrin process. The two reaction steps in the production of propene chlorohydrin in the first reactor (chlorohydrination) are production of the propene chloronium complex in the first reaction step,

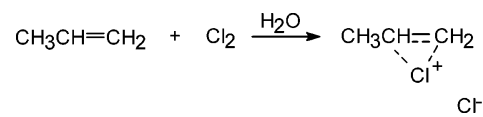

followed by a reaction with water to produce two propene chlorohydrin isomers.

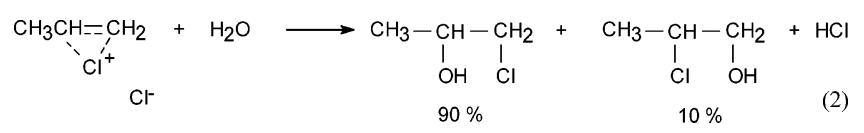

The selectivity of these reactions to the chlorohydrin isomers is $\sim 90 \%-95 \%$. The byproducts formed are primarily 1,2dichloropropane (from the gas-phase reaction of propene with chlorine) and smaller quantities of dichloropropanols (produced from allyl chloride, which is also formed in the gas phase from the reaction between propene and chlorine), as well as dichloroisopropyl ethers (from the reaction of the chloronium complex with propene chlorohydrin). The chlorohydrination is usually performed in a bubble column reactor at a pressure of 1.5 bar and temperature of $323 \mathrm{~K}$. Because of the corrosive nature of the reaction mixture, the use of rubber-, plastic-, or brick-lined equipment is necessary.
In the epoxidation reactor, the dehydrochlorination of propene chlorohydrin occurs using a base (usually calcium hydroxyde).

$$
\begin{aligned}
& \mathrm{CH}_{3}-\mathrm{CH}-\mathrm{CH}_{2} \\
& \text { I } \mathrm{OH} \\
& 2
\end{aligned}
$$

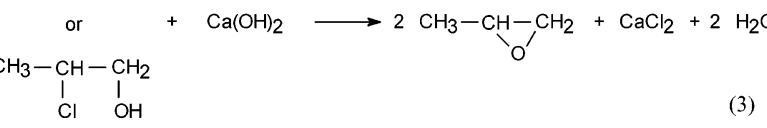

The propene oxide is steam-stripped from this reactor, to prevent base-catalyzed hydrolysis of the product. The dehydrochlorination is performed in the same column where the products are stripped from the wastewater stream (1 bar, $373 \mathrm{~K}$ ). The chlorinated hydrocarbons that are produced ultimately reside in the propene oxide stream and must be removed. The brine leaving the bottom of the reactor contains some propene glycols, because the hydrolysis of propene oxide cannot be completely avoided. These glycols and small amounts of other hydrocarbons present must be removed biologically. Subsequently, the brine is discharged, because the calcium chloride in the stream has no commercial value. This is one of the major disadvantages of the chlorohydrin process, because the amount of brine $(5 \%$ $\mathrm{CaCl}_{2}$ ) produced is usually $\sim 40$ times larger than the amount of propene oxide produced and it is extremely difficult to remove all hydrocarbons from this wastewater stream. Reuse of the calcium chloride is not economically feasible, because of its low commercial value. Alternatively, sodium hydroxide can be used instead of calcium hydroxide. This has an advantage in that the sodium chloride produced can then be used in the production of chlorine, which can be discharged easier or recycled in the first step of the process.,12 Therefore, this modification to the process is able to remove the environmental problem of this process, to a large extent.

The raw propene oxide stream must be purified by distillation from the water and chlorinated hydrocarbons. In this separation, again, care must be taken that the propene oxide is not hydrolyzed to propene glycol. The relatively large amount of 1,2-dichloropropane (up to $10 \%$ ) is obtained as a second "product" from the separation section. Because this compound has very little usage, it not only causes a loss in yield, but also creates a disposal problem. ${ }^{9}$ Alternatively, however, it is also possible to recycle the chlorinated propanes to propane or propene, ${ }^{13}$ which is a very effective way to improve the attractiveness of the process and reduce the environmental impact.

The two disposal problems (brine and chlorinated byproducts) are the main reason that no new chlorohydrin plants are built and old plants are closed down instead of being modernized. Only the large-scale plants (>100 000 tons/yr) are expected to remain operational for a longer period, because they are often integrated with chlorine production plants.

2. Hydroperoxide Processes. Hydroperoxide processes are based on the peroxidation of an alkane to an alkyl-hydroperoxide. These alkyl-hydroperoxides then react with propene, producing propene oxide and an alcohol. A characteristic of these processes is that, besides propene oxide, a coproduct is produced in a fixed ratio, usually $2-4$ times the amount of propene oxide produced. Currently, two variants of this process are applied commercially. The first is the propene oxide-styrene monomer (PO-SM, also commonly abbreviated as SMPO) process ( $\sim 60 \%$ of the hydroperoxide plants use this version).$^{14-16}$ In this process, ethylbenzene is oxidized to ethylbenzene hydroperoxide, which reacts with propene to produce propene oxide and $\alpha$-phenyl ethanol. The $\alpha$-phenyl ethanol is then dehydrated to produce styrene. The second process in use is 


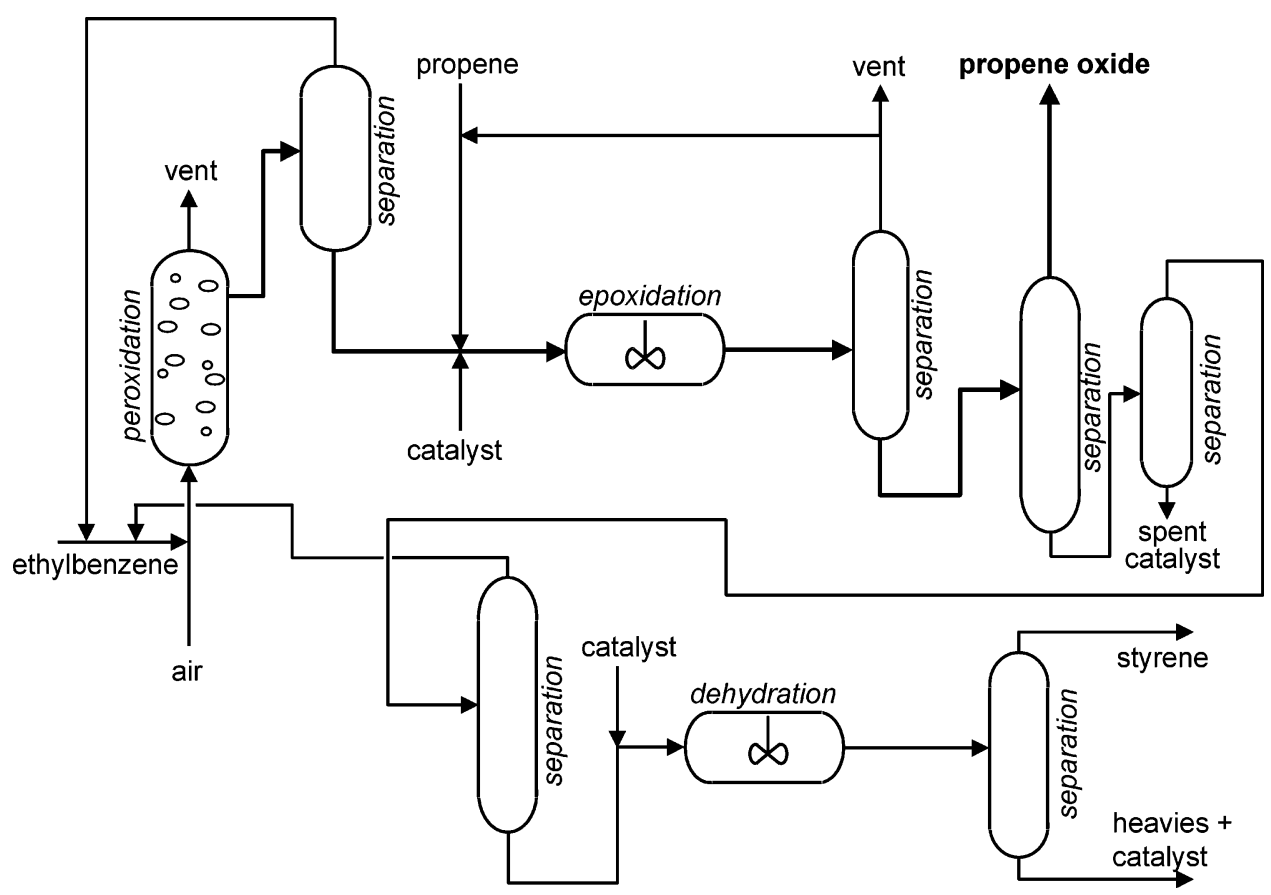

Figure 2. Schematic representation of the propene oxide-styrene monomer (PO-SM) process for the production of propene oxide.

the propene oxide-tert-butyl alcohol (PO-TBA) process. ${ }^{17,18}$ In this process, isobutane is oxidized to tert-butyl hydroperoxide (TBHP), which reacts with propene to produce propene oxide and tert-butyl alcohol. This can be dehydrated to isobutene or converted directly with methanol to methyl-tert-butyl ether (MTBE). Although other combination processes are possible, no others have been applied so far. Other possibilities include, for example, acetaldehyde to acetic acid, 2-propanol to acetone, isopentane (via tert-pentyl alcohol) to isoprene, cumene (via dimethylphenyl methanol) to $\alpha$-methylstyrene, and cyclohexene (via cyclohexanol) to cyclohexanone. Characteristics of the hydroperoxide processes are that they are selective and produce far less waste than the chlorohydrin process. However, the major disadvantage of the hydroperoxide processes is that a fixed amount of coproduct is always produced. Because the markets for propene oxide and the coproducts are not linked, a problem could arise, should the demand for one of the products collapse. Since the use of MTBE as a fuel additive is becoming less favorable (especially in the United States), the latest plants that have been built using a hydroperoxide process are all of the PO-SM type.

Figure 2 schematically demonstrates the $\mathrm{PO}-\mathrm{SM}$ process. The basic principle of the PO-TBA process is similar to that of the $\mathrm{PO}-\mathrm{SM}$ process, so both processes are discussed simultaneously. The first reactor converts the ethylbenzene or isobutane noncatalytically to its corresponding hydroperoxide by direct liquid-phase oxidation, using oxygen or air. The oxidation is usually performed in a bubble column at $400 \mathrm{~K}$ and 30 bar when isobutane is used, or $423 \mathrm{~K}$ and 2 bar in the case of ethylbenzene. The reaction equation of this reaction in the $\mathrm{PO}-$ $\mathrm{SM}$ process is

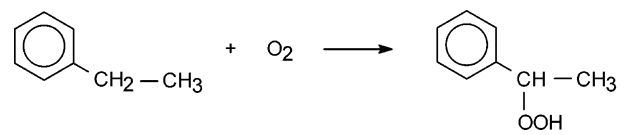

A disadvantage of the processes using isobutane is that a relatively large fraction of the TBHP that is produced immediately decomposes to TBA, thus reducing the ratio of propene oxide to coproduct. The unreacted hydrocarbons are removed and recycled. The hydroperoxide stream is sent to a second reactor, where it catalytically reacts with propene to produce propene oxide and an alcohol. The temperature in this reactor is $\sim 373 \mathrm{~K}$ at 30 bar pressure. The reactor used for the epoxidation is usually a compartmentalized reactor with staged propene feeding. The total conversion in the reactors is $>95 \%$ (of the hydroperoxide) at $>95 \%$ selectivity to propene oxide, and the only byproduct produced is acetone. Reaction 5 gives the epoxidation reaction in the $\mathrm{PO}-\mathrm{SM}$ process:

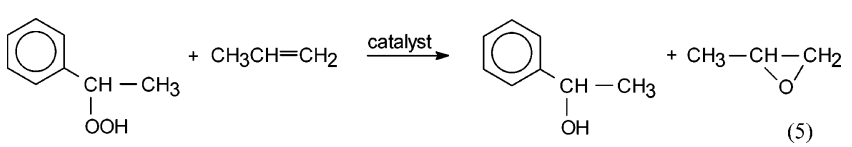

Most processes use either a homogeneous tungsten, molybdenum, or vanadium catalyst or a heterogeneous titanium-based catalyst to catalyze the epoxidation reaction. ${ }^{3,19}$ The disposal of a homogeneous catalyst causes a waste/separation problem. After the reactor, the propene and propene oxide are removed consecutively from the liquid stream. In case of the PO-SM process, the remaining stream still contains some unreacted ethylbenzene, which then is removed and recycled. The alcohol stream can then be dehydrated to produce styrene or isobutene, or, for the PO-TBA process, the tert-butyl alcohol can be used directly. An important side reaction that can occur in this dehydration is the oligomerization of the styrene produced, which results in a loss of catalyst activity and reduces the catalyst lifetime. $^{20}$

A process that is very closely related to these two hydroperoxide processes is operated by Sumitomo Chemical. ${ }^{21}$ In this process, cumene is oxidized to its hydroperoxide, which is used to produce propene oxide. The alcohol produced is subsequently converted back to cumene over a copper-chromium oxide catalyst to be reused in the process. The advantage of this process is that cumene is easier to hydroperoxidate (more stable) than styrene and that no coproduct is being produced. Propene oxide selectivities of $99 \%$ can be obtained, whereas $95 \%$ of the peroxide is used for the oxidation.

3. Ethene-Epoxidation-Type Silver Catalysts. 3.1. Ethene Epoxidation Process. Since the 1940s, all newly built plants 


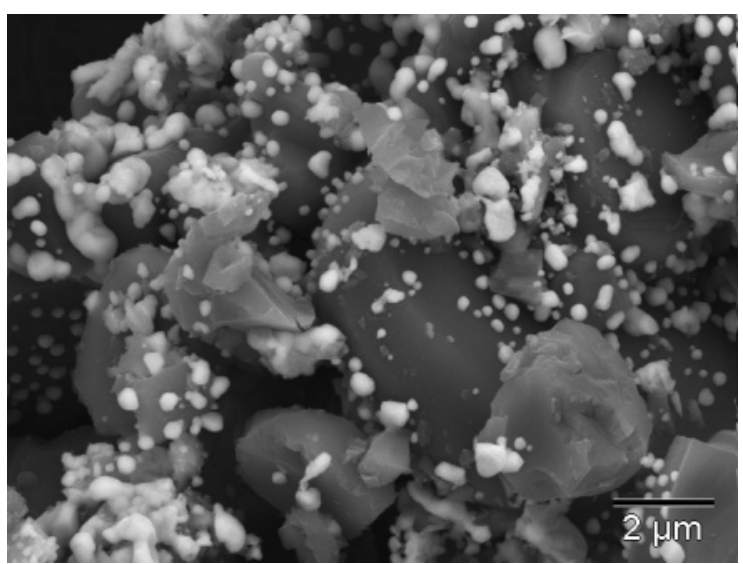

Figure 3. Typical scanning electron microscopy (SEM) image of silver (18 wt \%) on an $\alpha$-alumina catalyst, such as that used in ethene epoxidation processes. The silver particles are the light-colored particles visible in the picture. (Picture taken as a mixture between backscattered electrons $(30 \%)$ and secondary electrons $(70 \%)$, to get an optimal contrast between silver and alumina.)

for the production of ethene oxide have been based on a direct oxidation process using a silver catalyst. ${ }^{22} \mathrm{~A}$ fixed-bed reactor is used to epoxidize ethene at $500 \mathrm{~K}$ and 30 bar. A typical conversion in the reactor is $\sim 10 \%$, to prevent a further oxidation of the ethene oxide that is produced and to simplify the problems caused by the exothermicity of the reaction. This relatively low conversion explains why the use of pure oxygen is usually preferred instead of air, because this simplifies the separations necessary for the recycle stream. The catalyst used in the process is a $10-20 \mathrm{wt} \%$ silver catalyst supported on low-surface-area $\left(<1 \mathrm{~m}^{2} / \mathrm{g}\right) \alpha$-alumina that contains several promoters. A typical scanning electron microscopy (SEM) image of silver on an alumina catalyst, similar to that used for the epoxidation of ethene, is shown in Figure 3. The most important promoter on the catalyst itself is an alkali metal, which is used to reduce the catalyst acidity. Cesium chloride is often added to facilitate the desorption of the epoxide. ${ }^{23}$ The selectivity of the reaction is usually $\sim 90 \%$, with the remainder of the ethene being converted to carbon dioxide. Recently, this selectivity has been gradually increasing. ${ }^{24}$

3.2. Silver Catalyst. The ethane epoxidation silver catalyst has a high metal loading on a low-surface-area support, typically $\alpha$-alumina. The use of unsupported silver as a catalyst is also possible; however, this has a tendency to sinter at the reaction temperature. Other possible support materials include inert materials such as silicon carbide (which is also used commercially), glass wool, and quartz. All support materials have a low surface area, because microporous materials generally yield poor results, which is due to the occurrence of heat problems inside the particles and further oxidation of ethene oxide produced in the pores. ${ }^{22}$

Originally, the idea existed that the epoxidation of ethene over silver occurred by molecular oxygen, producing ethene oxide and atomic oxygen on the catalyst. The atomic oxygen then could only be removed from the catalyst via the complete oxidation of ethene. This model resulted in a maximum obtainable selectivity of $86 \%$. This seemed to be confirmed by the fact that higher selectivities had never been reached. However, during the last 20 years, this idea started to change and atomic oxygen has now been confirmed to be the active species in all recent studies. One of the first studies to clearly identify atomic oxygen as the active species was research that was conducted by van Santen and de Groot, ${ }^{25}$ who studied the initial reaction rates for silver surfaces precovered by either

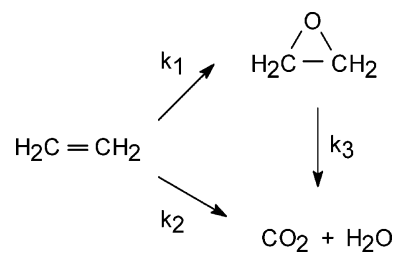

Figure 4. Reaction scheme for the epoxidation and combustion of ethene. atomic or molecular oxygen. In that study, the surfaces that were precovered with atomic oxygen had significantly higher ethene oxide production rates than the surfaces that were precovered with molecular oxygen.

An explanation for the unique characteristics of silver in the epoxidation of ethene is found in its ability to dissociatively adsorb oxygen, which is weakly bound at high coverages. ${ }^{26}$ If oxygen is unable to dissociate, the epoxidation will not occur. When the oxygen-metal bond is too strong, the formation of an epoxide is thermodynamically impossible. Oxygen adsorbed on silver is also able to activate the $\mathrm{C}-\mathrm{H}$ bond of ethene, explaining the selectivities that were $<100 \%$. However, this reaction is slower than the epoxidation reaction and the sites most active for this reaction can be blocked using promoters.

The generally accepted reaction scheme for the epoxidation of ethene over a silver catalyst is represented in Figure 4. This reaction scheme indicates that the complete oxidation occurs as both parallel and sequential reactions. The oxidation rate of the epoxide $\left(k_{3}\right)$ is very small, compared to reactions 1 and $2 .{ }^{27}$ The reactions are zero order in oxygen and first order in ethene, within the operating window of the process. When the same silver catalyst is applied in the epoxidation of propene, the reaction scheme in Figure 4 is also determined to be valid and identical reaction orders are found; however, the selectivity toward propene oxide is very low (usually $<10 \%$ ). The rate constant for the complete oxidation of propene oxide is again extremely low and negligible. The low selectivity for propene oxide is primarily caused by the high rate of the complete oxidation of propene, which is almost a factor of 10 faster than the complete oxidation of ethene. On the other hand, the epoxidation reaction of propene is almost a factor of 10 slower than the epoxidation reaction of ethene. The next paragraph discusses the differences in reactivity of propene and ethene on a molecular scale to explain these differences in reactivity.

3.3. Reaction Mechanism in the Ethene and Propene Epoxidation. Carter and Goddard ${ }^{28}$ presented a comprehensive oxyradical mechanism to explain the differences in reactivity of ethene and propene in both the epoxidation and the complete combustion. This mechanism is based on valence-bond calculations on the thermodynamics of the different reaction steps and is verified by experimental results. The active species is assumed to be a surface atomic oxyradical, which is adsorbed atomic oxygen with its unpaired electron pointing away from the catalyst surface. This is in contrast to the di- $\sigma$ oxide-type oxygen, which has both electrons bonded to the silver surface. The thermodynamic calculations suggest that the oxyradical type oxygen will only form at higher oxygen surface coverages. This is consistent with reported higher epoxidation selectivities at higher oxygen surface coverages. ${ }^{26}$ This increasing selectivity of the silver catalyst at an increasing oxygen coverage was explained by Lambert et al. ${ }^{29}$ by a decreasing valence charge density. The most common promoter for the reaction, chlorine, has a similar electronic effect on the adsorbed atomic oxygen: chlorine (or another halogen) adsorbed on silver decreases the valence charge on oxygen adatoms, thereby favoring $\mathrm{O}$-insertion into the $\mathrm{C}=\mathrm{C}$ bond, rather than $\mathrm{C}-\mathrm{H}$ cleavage followed by combustion. 


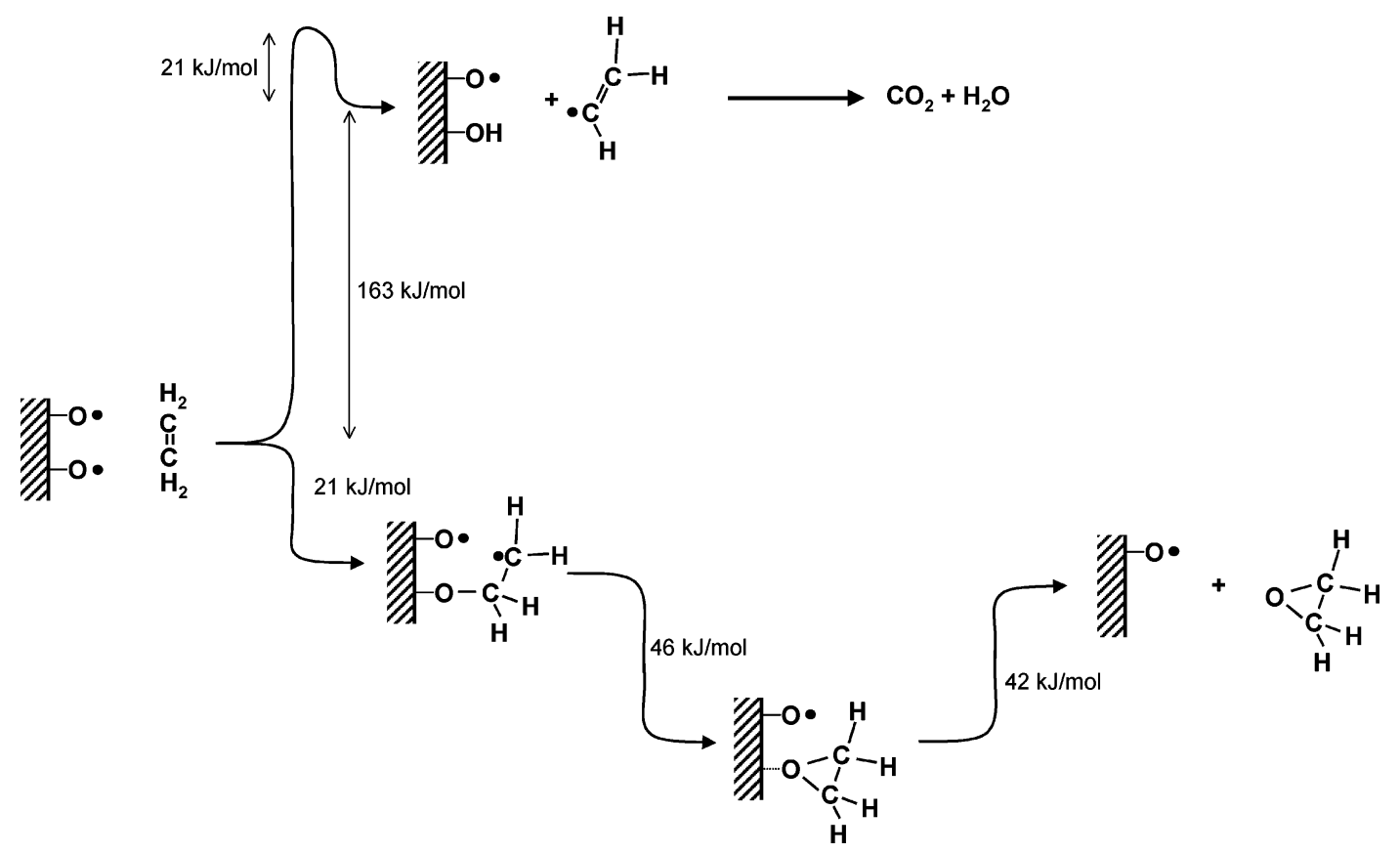

Figure 5. Reaction scheme for the epoxidation and total oxidation reaction pathways for ethene over a silver catalyst. ${ }^{28}$

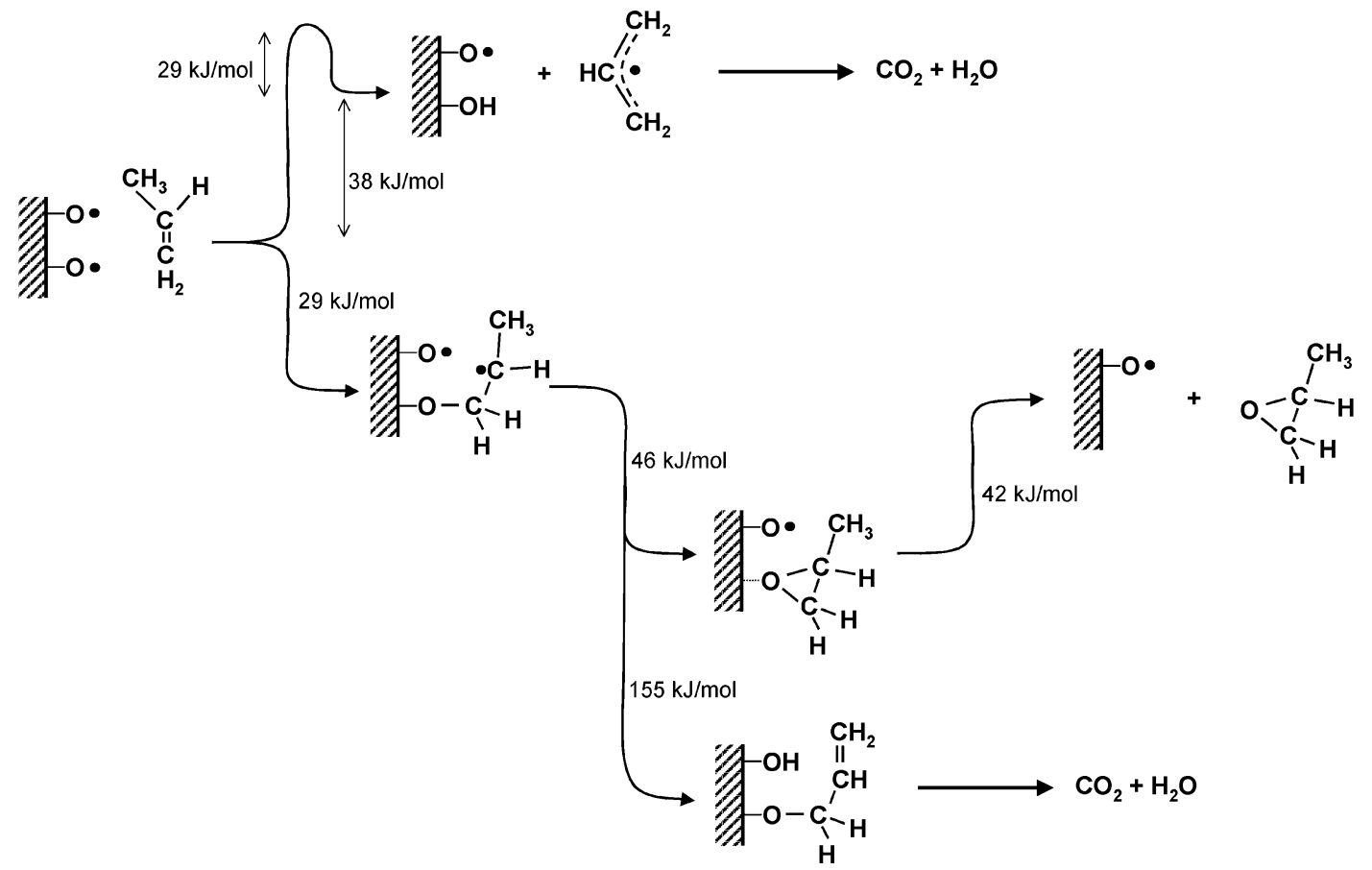

Figure 6. Reaction scheme for the epoxidation and total oxidation reaction pathways for propene over a silver catalyst. ${ }^{28}$

Figure 5 demonstrates the energy levels calculated by Carter and Goddard ${ }^{28}$ for both the epoxidation and combustion of ethene over atomic oxygen on a silver surface. When ethene reacts with oxygen, the reaction can proceed two ways. The first possibility is the $\mathrm{C}-\mathrm{H}$ cleavage, causing the abstraction of a $\mathrm{H}$ atom. This reaction has a relatively high activation energy (184 kJ/mol), and once this reaction step has occurred, the only possible subsequent reaction steps result in the complete combustion of ethene. On the other hand, O-insertion into the $\mathrm{C}=\mathrm{C}$ bond, caused by an oxyradical attack on the double bond, is able to proceed without a significant activation to produce an oxygenated reaction intermediate. This intermediate can subsequently produce adsorbed ethene oxide, with the desorption of the epoxide only having a small barrier energy $(42 \mathrm{~kJ} / \mathrm{mol})$. This scheme is consistent with a decrease in epoxidation selectivity at higher temperatures, ${ }^{25}$ because the initial barrier for the combustion precursor will then be less of a problem.

When the scheme for the reaction of ethene is compared to that of propene in Figure 6, it can be seen that these are largely analogous. For propene, the direct abstraction of a $\mathrm{H}$ atom is more favorable than that for ethene, because propene is able to produce an allyllic intermediate. This allyllic intermediate results in a significantly lower barrier energy $(67 \mathrm{~kJ} / \mathrm{mol})$ for the direct combustion step, which can partly explain the lower epoxidation selectivity for propene. The initial reaction of the oxyradical with propene to produce the epoxide precursor is thermodynamically somewhat more favorable for propene than for ethene (21 kJ/mol for ethene, $29 \mathrm{~kJ} / \mathrm{mol}$ for propene), which could partly compensate for this decrease in selectivity. A bigger problem is the propene epoxide precursor. It has an alternative 
Table 1. Comparison between Measured Conversions and Selectivities for the Epoxidation of Ethene, Propene, and 3,3-Dimethyl-1-butene ${ }^{a}$

\begin{tabular}{lcc}
\hline \multicolumn{1}{c}{ gas } & $\begin{array}{c}\text { conversion } \\
(\%)\end{array}$ & $\begin{array}{c}\text { epoxidation selectivity } \\
(\%)\end{array}$ \\
\hline ethene & 17.8 & 47.4 \\
propene & 7.5 & 6.0 \\
3,3-dimethyl-1-butene & 4.0 & 25.0
\end{tabular}

${ }^{a}$ Data taken from ref 30. Conditions were as follows: $6.6 \mathrm{~g}$ of ethene epoxidation-type silver catalyst ( $18 \mathrm{w} \% \mathrm{Ag}$ on $\left.\alpha-\mathrm{Al}_{2} \mathrm{O}_{3}\right) ; 1.7$ bar; $498 \mathrm{~K}$; $54 \mathrm{NmL} / \mathrm{min}$ flow; composition of $11 \% \mathrm{O}_{2}, 33 \%$ alkene, and $56 \% \mathrm{~N}_{2}$.

reaction pathway available in addition to the epoxidation reaction, as in the case for ethene epoxide precursor. The $\gamma-\mathrm{H}$ atoms of the propene oxide reaction intermediate extend $\sim 0.27$ $\mathrm{nm}$ across the surface from the location where the reaction with the first $\mathrm{O}$ atom occurred. The distance between the different $\mathrm{O}$ atoms on the surface is $\sim 0.29 \mathrm{~nm}$, which is close enough for the $\gamma-\mathrm{H}$ atoms to reach. The abstraction of one of these $\mathrm{H}$ atoms is favorable and the intermediate formed can only result in a complete combustion of the molecule. This same reaction intermediate will probably also be produced, when the allylic intermediate that is produced from the direct hydrogen abstraction of propene is completely oxidized. The reaction step, in which the epoxide precursor reacts with a neighboring $\mathrm{O}$ atom, does not occur with ethene, because it has no $\gamma-\mathrm{H}$ atoms and abstraction of a $\beta-\mathrm{H}$ atom would result in the production of an unstable carbene, which would have a high energy barrier.

A check on this mechanism can be made by comparing the reactivity of compounds with and without $\gamma$-H atoms. Under identical conditions, the reactivity and selectivity toward the epoxidation of ethene, propene, and 3,3-dimethyl-1-butene were determined. The results of these experiments are given in Table $1 .^{30}$ This table shows that the selectivity for epoxidation of ethene and dimethylbutene is significantly higher than the propene epoxidation selectivity. No conclusions can be drawn from the conversions on the reactivities of the different gases, because, in the experiments, the conversion was limited by the amount of oxygen present. Therefore, higher epoxidation selectivities can result in a higher conversion, and the combustion of longer hydrocarbons naturally results in lower conversions. These measurements are in agreement with reported selectivities on other alkenes without $\gamma-\mathrm{H}$ atoms, such as norbornene and styrene. ${ }^{31}$ However, it is difficult to distinguish whether the higher selectivities for dimethylbutene, norbornene, and styrene are caused by a lower direct hydrogen abstraction rate or are due to a lower hydrogen abstraction rate of the oxygenated intermediate on the catalyst surface. These tested compounds all lack the allylic stabilization of the intermediate that is formed after the direct hydrogen abstraction. However, because these components possess a significantly larger amount of $\mathrm{H}$ atoms, it would be expected that the direct hydrogen abstraction rate would be relatively higher. Eastman is able to selectively epoxidize butadiene over a silver catalyst with a high selectivity, because this molecule also does not have the reactive allylic $\mathrm{H}$ atoms. This reaction has been discussed in detail by Monnier. ${ }^{23}$

Assuming that high selectivities over a silver catalyst can be obtained for the propene epoxidation if one were able to block the hydrogen abstraction of the oxygenated surface intermediate, it naturally comes to mind that this might be achieved by increasing the distance between the $\mathrm{O}$ atoms on the silver surface. The easiest way to establish this would be to reduce the oxygen surface occupancy on the catalyst. However, at reduced oxygen coverages, the valence charge density of the adsorbed oxygen increases, causing the selectivity to decrease

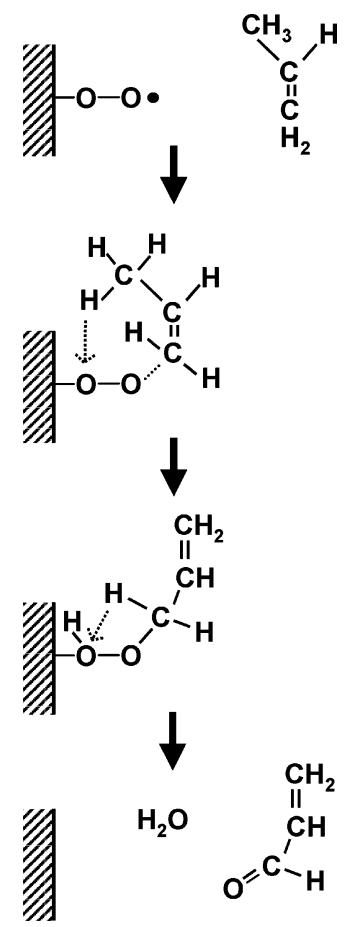

Figure 7. Reaction scheme for conversion of propene to acrolein over an isolated-site silver catalyst. ${ }^{27}$

dramatically. ${ }^{29}$ Another possibility is to increase the distance between the Ag sites on the catalyst. This type of catalyst can be created by alloying the silver with an inert material.

An isolated-site silver catalyst can easily be created by alloying gold with silver. Silver and gold are able to form stable alloys (exothermally) in every composition, and gold is totally inactive in either propene epoxidation or combustion in the temperature range used for epoxidation. In a study by Geenen et al., ${ }^{27}$ both the epoxidation of ethene and propene over supported silver-gold alloy catalysts were examined. In their study, they determined the epoxidation activities for both ethene and propene at gold surface contents up to $50 \%$. However, the epoxidation selectivity decreased as the gold content increased, which is an observation that was also made by Toreis and Verykios $^{32}$ for the ethene epoxidation over gold-silver alloy catalysts. Geenen did not observe changes in the reaction rate as a function of the gold content. In the case of the oxidation of propene, the catalyst started making an increasing amount of acrolein when more gold was added (no acrolein production is detected in the absence of gold). This selectivity toward acrolein reaches almost $100 \%$ at a gold content of $>75 \%$ on the surface. This is explained by the presence of isolated $\mathrm{Ag}$ sites at the catalyst. These sites are unable to dissociate oxygen, and, therefore, oxygen only adsorbs in molecular form. This molecular adsorbed oxygen can react with propene, according to the mechanism in Figure 7, producing acrolein.

3.4. Outlook toward the Possibility of a Propene-Epoxidizing Silver Catalyst. If one summarizes the models mentioned in the previous paragraphs, two important points remain:

(1) A significant portion of the combustion of propene is caused by the reaction of $\gamma-\mathrm{H}$ atoms of an adsorbed oxygenated propene oxide precursor with a neighboring adsorbed $\mathrm{O}$ atom; and

(2) Propene oxide is formed from atomic oxygen only. The active oxygen species exists only at relatively high oxygen coverages.

By combining these points, it can be concluded that if one is able to create a silver catalyst with isolated active sites and put 


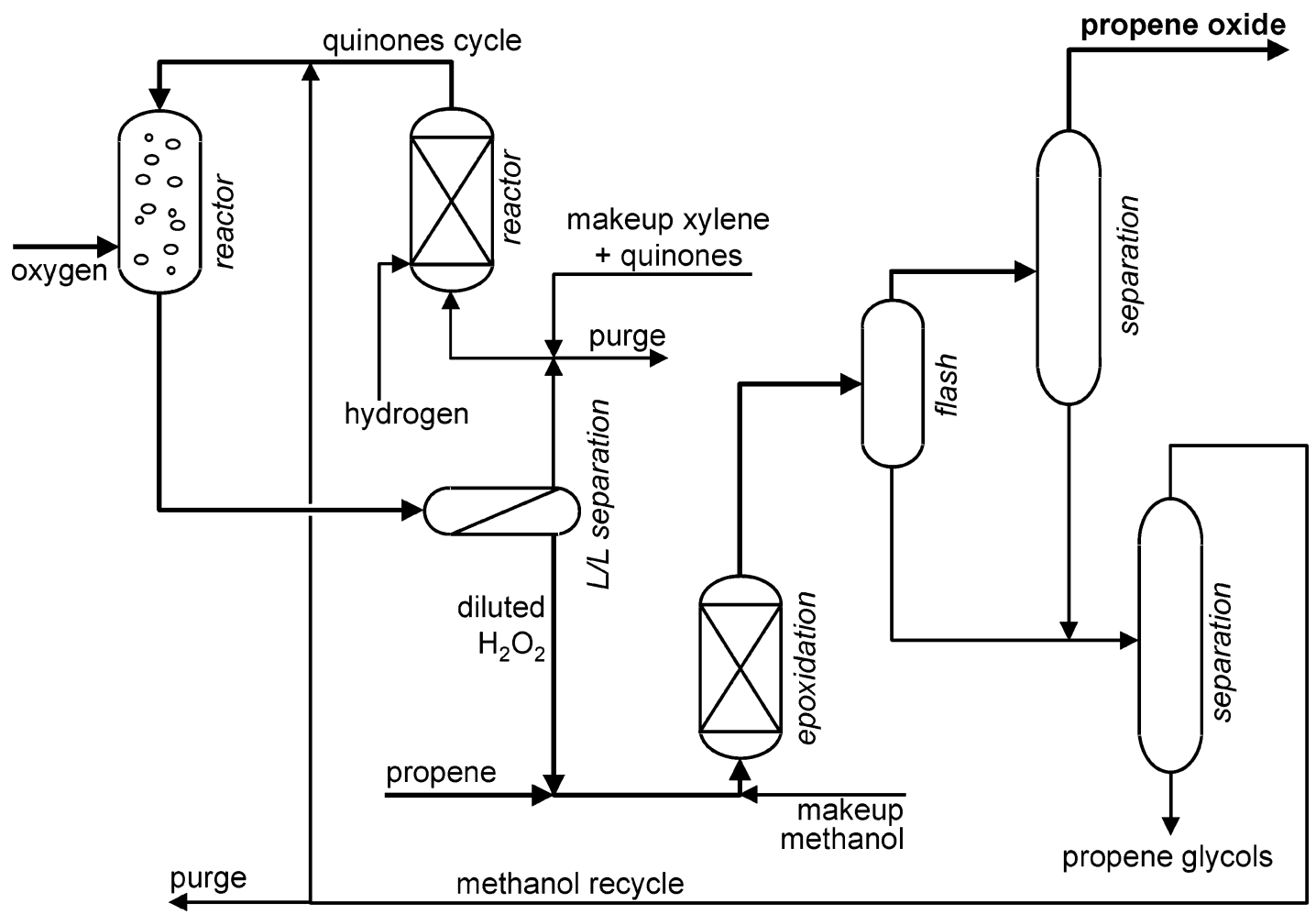

Figure 8. Suggested flow scheme for a propene epoxidation process by integrating a anthrahydroquinone hydrogen peroxide production process with a propene epoxidation reaction catalyzed by TS-1.

atomic oxygen on these sites, this catalyst should be able to make propene oxide selectively, provided that it is not necessary for propene to adsorb on the catalyst next to the oxygen. The calculations by Carter and Goddard ${ }^{28}$ confirm that a separate propene adsorption is not necessary. A relatively simple way to create the catalyst is to use a silver-gold alloy. Because it is necessary to create atomic oxygen on this catalyst and (di)oxygen does not dissociate on the isolated sites, an alternative way of providing atomic oxygen must be found. A possibility could be the use of nitrous oxide $\left(\mathrm{N}_{2} \mathrm{O}\right)$, because silver is a good catalyst for the decomposition of nitrous oxide. ${ }^{27}$ Although this concept should work in theory for the production of propene oxide, attempts to prepare a working catalyst so far have been unsuccessful. ${ }^{30}$

A variety of the classical ethene-epoxidation silver on an $\alpha$-alumina catalyst has been developed over the past years by ARCO (now Lyondell). ${ }^{21,33-35}$ This catalyst, especially for the propene epoxidation, consists of high-loaded (typically 30\%$60 \%$ ) silver on a calcium carbonate catalyst that contains potassium, molybdenum, and chlorine promoters. In the propene epoxidation in the presence of chloroethane, nitric oxide, and carbon dioxide, a very promising propene oxide selectivity of almost $60 \%$ was obtained at a conversion of $3 \% .{ }^{34}$ For this catalyst, it is shown that, contrary to the ethene oxide silver catalyst, smaller silver particles are considerably more selective for the epoxidation. ${ }^{33}$ The reason this catalyst performs so much better for the propene epoxidation is not yet clear. However, the development of this catalyst system undoubtedly brings a commercially attractive silver catalyst for the propene epoxidation considerable closer.

More recently, silver has also been used as a propene epoxidation catalyst in cooperation with titania. ${ }^{36,37}$ In this case, both hydrogen and oxygen are needed to perform the epoxidation. The reaction mechanism is expected to be similar to that of the gold-titania catalysts that are discussed in one of the next paragraphs. However, the performance (conversion and selectivity) of these silver catalysts is considerably less than that of the gold-titania catalysts.

4. Hydrogen Peroxide Combination Process. A recent development in the production of propene oxide is the production of propene oxide using hydrogen peroxide produced in integrated process. ${ }^{7,38-40}$ Although commercially available hydrogen peroxide is no alternative as an oxidizing agent for the epoxidation of propene, because of its high cost, this process is viable if the hydrogen peroxide is produced in situ. The most expensive step in many chemical processes is the separation of the products, which is also the case for the production of hydrogen peroxide. Currently, most hydrogen peroxide is produced using the anthrahydroquinone autoxidation process. ${ }^{41}$ In this process, the hydrogen peroxide is produced in diluted form in a water-methanol mixture. The zeolite titanium silicalite-1 (TS-1) is able to very selectively epoxidize propene using diluted hydrogen peroxide. ${ }^{6,42}$ For this reaction, many other catalysts also are possible, and an excellent overview of these is given by Lane and Burgess. ${ }^{43}$

A cost-saving feature in this process is that, instead of separating the hydrogen peroxide produced, it can be used directly in the epoxidation of propene. The separation of the propene and propene oxide from the water-methanol mixture can easily be accomplished, which allows an excellent integration of a hydrogen peroxide process and a propene epoxidizing process. This integrated process was originally under development by Enichem ${ }^{38}$ but finally commercialized by Dow-BASF. ${ }^{7}$ The technology used for the production of hydrogen peroxide is provided by Solvay, which participates in a joint venture with BASF to provide the hydrogen peroxide needed for the epoxidation. ${ }^{44}$ At this moment, a plant is under construction in Antwerp, Belgium, with more planned to be built soon.

A simplified representation of such an integrated process is given in Figure 8. The two reactors in the left portion of this figure depict the hydrogen peroxide synthesis from hydrogen and oxygen using anthrahydroquinones, and the reactor in the 
center is the epoxidation reactor. When the quinones used in this process are alternately oxidized and reduced, they produce hydrogen peroxide. The oxidation and reduction are performed in two separate reactors. A bubble column is applied for the oxidation of the quinones, during which the hydrogen peroxide is produced. For the palladium-catalyzed hydrogenation of the quinones, a slurry, fixed bed, or monolith reactor can be used. Both hydrogenation and oxidation are performed at $\sim 320 \mathrm{~K}$ and 1.2 bar. Reactions 6 and 7 show the hydrogen peroxideproducing reactions of the quinones for the most commonly used 2-ethylanthrahydroquinone.
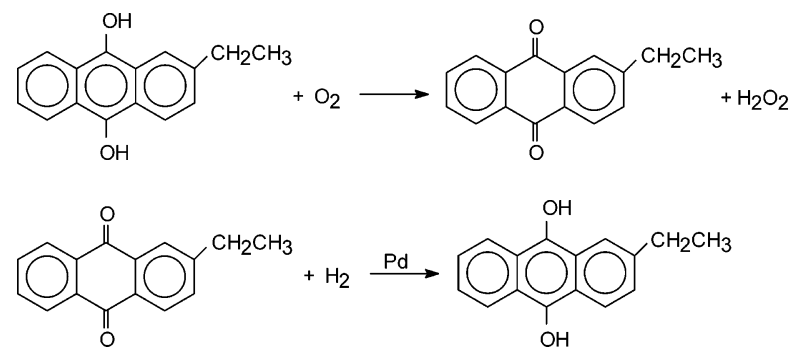

The hydrogen peroxide synthesis is performed in a mixture of a hydrophobic (e.g., xylene) and a hydrophilic (water + methanol) phase. These phases are separated using a settler after which a hydrogen peroxide-containing water-methanol stream is obtained. The hydrogen peroxide in this stream is used to epoxidize propene (at close to $100 \%$ conversion), using TS-1 as a catalyst.

$\mathrm{H}_{2} \mathrm{O}_{2}+\mathrm{CH}_{3} \mathrm{CH}=\mathrm{CH}_{2} \stackrel{\mathrm{TS}-1}{\longrightarrow} \mathrm{H}_{2} \mathrm{O}+\mathrm{CH}_{3}-\underset{\mathrm{O}^{\prime}}{\mathrm{CH}}-\mathrm{CH}_{2}$

The epoxidation reaction using TS- 1 is conducted in a fixedbed reactor at $313 \mathrm{~K}$ and atmospheric pressure. After some relatively simple separation steps, the propene oxide is obtained and the water-methanol mixture is returned into the hydrogen peroxide synthesis.

Although it is also possible to use other catalysts, such as molybdenum oxide or tungsten oxide, to epoxidize propene with hydrogen peroxide, these catalysts are all extremely sensitive to the presence of water. ${ }^{45,46}$ Homogeneous catalysts are not preferred, because of additional separation costs.

A comparable route for the production of propene oxide is being commercialized by Degussa-Headwaters. ${ }^{39}$ They successfully integrated a process to produce propene oxide using hydrogen peroxide with the new Degussa-Uhde process for the direct production of hydrogen peroxide from hydrogen and oxygen.

A different approach in this epoxidation route would be to perform all three reactions (the oxidation and reduction of the quinones and the epoxidation) in the same reactor. ${ }^{40}$ This process was demonstrated on a laboratory scale; however, the practical application of the process will be complicated by the explosive nature of a hydrogen-oxygen mixture. Furthermore, the production of hydrogen peroxide using quinones in a single reactor has not yet been applied, making the single reactor approach more precarious than the split reactor process. One option might be to produce hydrogen peroxide using gold catalysts; ${ }^{47,48}$ however, this system is still in an early stage of research. It has been demonstrated that propene oxide can be produced on the laboratory scale, using a Pd-Pt/TS-1 catalyst, which also produces the hydrogen peroxide in situ. ${ }^{49}$ However, catalyst deactivation and the oxidation of the methanol solvent are still a major problem. Therefore, the actual application of the process shown in Figure 8 is more feasible, because this process can easily be integrated with an existing hydrogen peroxide production facility and is more flexible, because it can also be applied for other TS-1 catalyzed oxidations using hydrogen peroxide.

5. Other Processes. 5.1. Epoxidation Using Nitrous Oxide. An alternative oxidizing agent for the epoxidation of propene that has been extensively investigated is nitrous oxide $\left(\mathrm{N}_{2} \mathrm{O}\right) .{ }^{50-52}$ Especially after the discovery of Panov, ${ }^{53}$ that $\mathrm{Fe}-\mathrm{ZSM}-5$ zeolite selective oxidations could be performed using nitrous oxide, this oxidant has received much attention for many different oxididation reactions. ${ }^{54}$ For a potassium-promoted iron oxide on SBA-15 catalyst propene oxide, selectivities of up to $80 \%$ have been obtained at conversions of up to $5 \%,{ }^{55}$ which would be sufficient to run a propene epoxidation process. A major disadvantage for an oxidation process using nitrous oxide for a bulk chemical such as propene oxide, however, is that nitrous oxide is not commercially available in large quantities. Virtually all nitrous oxide currently produced is produced as a byproduct of the adipic acid production using the nitric oxide production of cyclohexanol. ${ }^{56}$ If one were to produce propene oxide using nitrous oxide, it would be necessary to place the production facility close to an adipic acid plant. The largestscale adipic acid plants that are currently in use produce $\sim 300000$ tons of adipic acid per year. Although these adipic acid processes can produce nitrous oxide in equimolar amounts, the amount of propene oxide produced as a coproduct next to adipic acid could, by estimate, be only 30000 tons/yr, which is only a very small-scale production of propene oxide. If one were to envision this process as a way of disposing of the harmful (greenhouse gas) nitrous oxide, this could be a moderately profitable process.

If one would want to produce larger quantities of propene oxide, it would be necessary to produce nitrous oxide especially for this purpose by converting ammonia. However, one would then effectively be using $>1 \mathrm{~mol}$ of methane to produce $1 \mathrm{~mol}$ of nitrous oxide, which would be not very efficient. The use of nitrous oxide as an oxidant is discussed in more detail by Lange. $^{57}$

5.2. Epoxidation Using Molten Salts. A conceptual process for the epoxidation of propene using molten alkali-nitrate salts was developed by Olin. Olin has filed a large number of patents on this process (see, e.g., refs 5 and 58-61), the latest of which dates back to $1991 .{ }^{61}$ In this process, at a pressure of 20 bar and a temperature of $473 \mathrm{~K}$, a propene oxide selectivity of $65 \%$ at $15 \%$ propene conversion is reported when a propene-air mixture is flowed through a molten alkali-nitrate salt mixture. The major byproducts are aldehydes, carbon monoxide, and carbon dioxide. Recirculation of the aldehydes resulted in an increased selectivity. Higher selectivities have been reported when a supported palladium co-catalyst is used ${ }^{58}$ or when sodium hydroxide is added to the molten salt. ${ }^{59}$ Using the same molten salt systems, it has also been reported that propane can be directly epoxidized to propene oxide. ${ }^{60}$ However, the reported selectivities for the epoxidation of propane are low $(<15 \%)$. Note that the reported high epoxidation selectivity of $65 \%$ with a propene conversion of $15 \%$ should be sufficiently high to run a profitable direct epoxidation process.

In a study by Nijhuis et al. ${ }^{62}$ into the molten salt catalysts, it was shown that the function of the molten salt was not a true catalytic one, but that the molten salt only is the initiator of a homogeneous gas-phase reaction. In several reports on the propene epoxidation using a homogeneous gas-phase reaction, ${ }^{63-65}$ high propene oxide yields have been obtained. After their molten salt patents, Olin also patented a process in which propene oxide was produced in a homogeneous gas-phase reaction ${ }^{66}$ at a 
selectivity of up to $65 \%$ at $7 \%$ propene conversion. The disadvantage of performing the propene epoxidation in a homogeneous gas-phase reaction is that it is extremely sensitive to the reactor and operation conditions. In studies that have been performed under similar conditions in the literature, very different conversions and selectivities have been obtained. ${ }^{62-65}$ Furthermore, the large amount of (side) product produced makes the separation expensive. However, if one should be able to operate a process for the propene epoxidation in a homogeneous gas-phase reaction in a controlled manner (whether in the presence or absence of a molten salt), this is a promising method, given the propene oxide yields that have been reported.

5.3. Homogeneous Catalysts. Although a large number of homogeneous catalytic systems ${ }^{67}$ are available to epoxidize alkenes, almost all of these catalysts only use hydroperoxides as oxidant. ${ }^{46}$ Using these hydroperoxides, high selectivities $(>90 \%)$ at moderate propene conversions (10\%) can be obtained. ${ }^{68}$ When (di)oxygen is used as an oxidant, on the other hand, the epoxidation selectivities are usually much lower $(<15 \%),{ }^{69}$ although higher selectivities (up to $50 \%$ at $12 \%$ conversion) are also reported. ${ }^{70}$ A major problem of moreselective homogeneous catalysts is that the catalyst is being consumed during the reaction. ${ }^{71}$ This consumption can usually be explained by one of the following two reasons. First, when the "catalyst" oxidizes propene, it cannot be reoxidized by molecular oxygen. Second, when the "catalyst" takes up an oxygen molecule $\left(\mathrm{O}_{2}\right)$, it epoxidizes propene and loses one $\mathrm{O}$ atom. The second $\mathrm{O}$ atom remains bonded to the "catalyst". This latter $\mathrm{O}$ atom is not active in the epoxidation reaction and the catalyst is deactivated. The catalyst could, in this case, be reactivated by reduction in a second reactor.

Although some of the homogeneous catalysts found so far are performing better than most heterogeneous systems, no processes based on these homogeneous catalysts are applied. An explanation can be found in the general disadvantages of homogeneous catalysts: the necessity of an extra separation of the catalyst from the liquid stream leaving the reactor and the loss of catalyst and/or ligand(s). Because propene has a high vapor pressure, the use of a solvent for the reaction will also be necessary, unless one is prepared to operate the process at a high pressure. Because propene oxide is a cheap bulk chemical, these extra costs (separation and pressure) can make a homogeneous process a costly one. Nevertheless, it might be worthwhile to consider homogeneous processes, because they are successfully applied in other selective oxidation processes, e.g., the production of terephthalic acid and the Wacker oxidation of ethene.

5.4. Gold-Titania Catalysts. Approximately eight years ago, gold-on-titania catalysts were reported for the first time by Haruta et al. as selective catalysts for the direct epoxidation of propene. $^{8}$ The largest advantage of these catalysts for the propene epoxidation is that they are capable of epoxidizing propene very selectively (selectivities of $99+\%$ are very common) under mild conditions (typically $323 \mathrm{~K}$ and 1 bar). The original application of catalysts based on gold nanoparticles was the low-temperature $\mathrm{CO}$ oxidation. ${ }^{72}$ Since that time, these catalysts have received a considerable amount of attention from many groups over the past year. ${ }^{73-85}$ Despite all this attention, the mode of operation of these catalysts for the propene epoxidation is still a matter of discussion. Both gold and titania seem to be a necessity for a catalyst to be able to epoxidize propene, although propene oxide also can be produced in a similar manner using silver on titania ${ }^{37}$ or gold on silica ${ }^{86}$ at a lower selectivity. The fact that this oxidation reaction requires

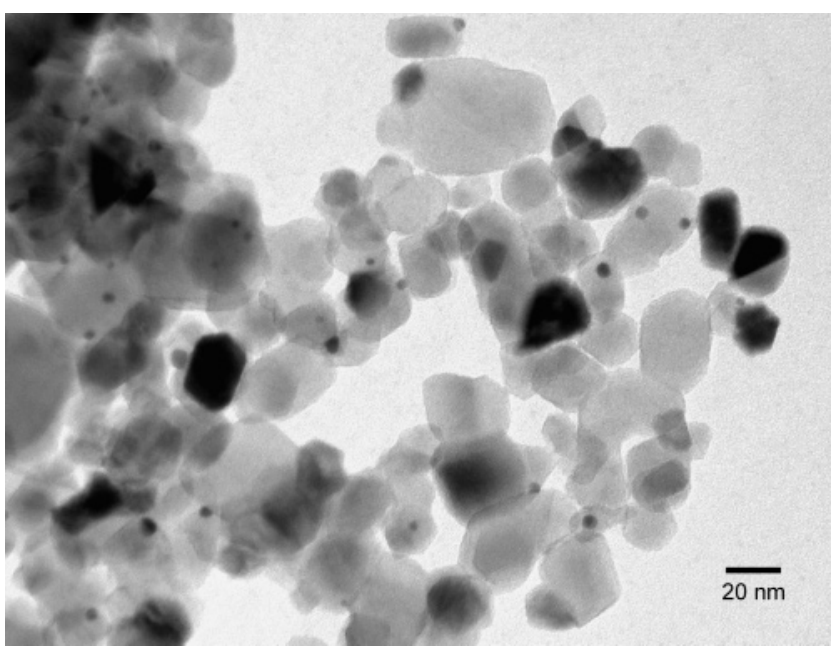

Figure 9. Transmission electron microscopy (TEM) picture of a typical $\mathrm{Au} / \mathrm{TiO}_{2}$ catalyst. $^{86}$ The gold particles are the large $(2-6 \mathrm{~nm})$ round dark particles visible in the picture supported on the lighter-colored large (20$60 \mathrm{~nm}$ ) titania particles. The larger dark particles are thicker titania particles.

hydrogen to be present next to oxygen, as well as the fact that propene can be epoxidized very selectively by hydrogen peroxide over titania, creates the common assumption that the reaction mechanism involves a peroxide species that would be produced by gold. ${ }^{87-89}$ Theoretical calculations have shown that, indeed, $\mathrm{OOH}^{90}$ or hydrogen peroxide ${ }^{91,92}$ can be produced on small gold particles. However, currently, no experimental evidence exists that this is also occurring during the propene epoxidation, which makes this peroxide mechanism speculative.

Gold-on-titania catalysts still need considerable improvements for them to be made attractive for application in a large-scale process. The main issues that must be addressed are the activity, the hydrogen efficiency, and the catalyst stability..$^{93,94}$ Typically, at this time, the "normal" gold-on-titania catalysts have a propene conversion of up to $1 \%$ with a propene oxide selectivity of $>95 \%$ and a hydrogen efficiency on the order of $30 \%$ (the hydrogen efficiency is defined as the amount of propene oxide produced divided by the amount of hydrogen consumed). Both a higher conversion level to propene oxide and a higher hydrogen efficiency will be needed for profiting process economics, because, otherwise, the costs of both the hydrogen and the separations will be too high. ${ }^{24}$

A key parameter for the catalytic activity is believed to be the shape and size of the gold particle. Haruta and co-workers ${ }^{8,95}$ have shown that hemispherical gold particles $2-5 \mathrm{~nm}$ in size are optimal for the epoxidation. Particles smaller than $2 \mathrm{~nm}$ catalyze the hydrogenation of propene to propane, because of the different electronic properties of the gold. Particles that are too large have a relatively higher selectivity toward the combustion. Most likely, this is caused by a decreasing goldtitania interface, when expressed per quantity of gold, which is seen as the site/area where the epoxidation occurs. Spherical gold particles are also less active than hemispherical particles, because they have a relatively smaller gold-titania interface. For the CO oxidation, Chen and Goodman ${ }^{73}$ showed that there is a large promotional effect for titania on gold when gold is deposited as a well-defined layer on it. For gold particles on a support, this effect will be largest when the contacting surface area is largest, which supports the observation from Haruta. A picture of a typical gold-on-titania catalyst that can be used for the epoxidation of propene is shown in Figure 9.

Figure 10 shows the reaction mechanism for the propene epoxidation over gold-titania catalysts, such as that most 


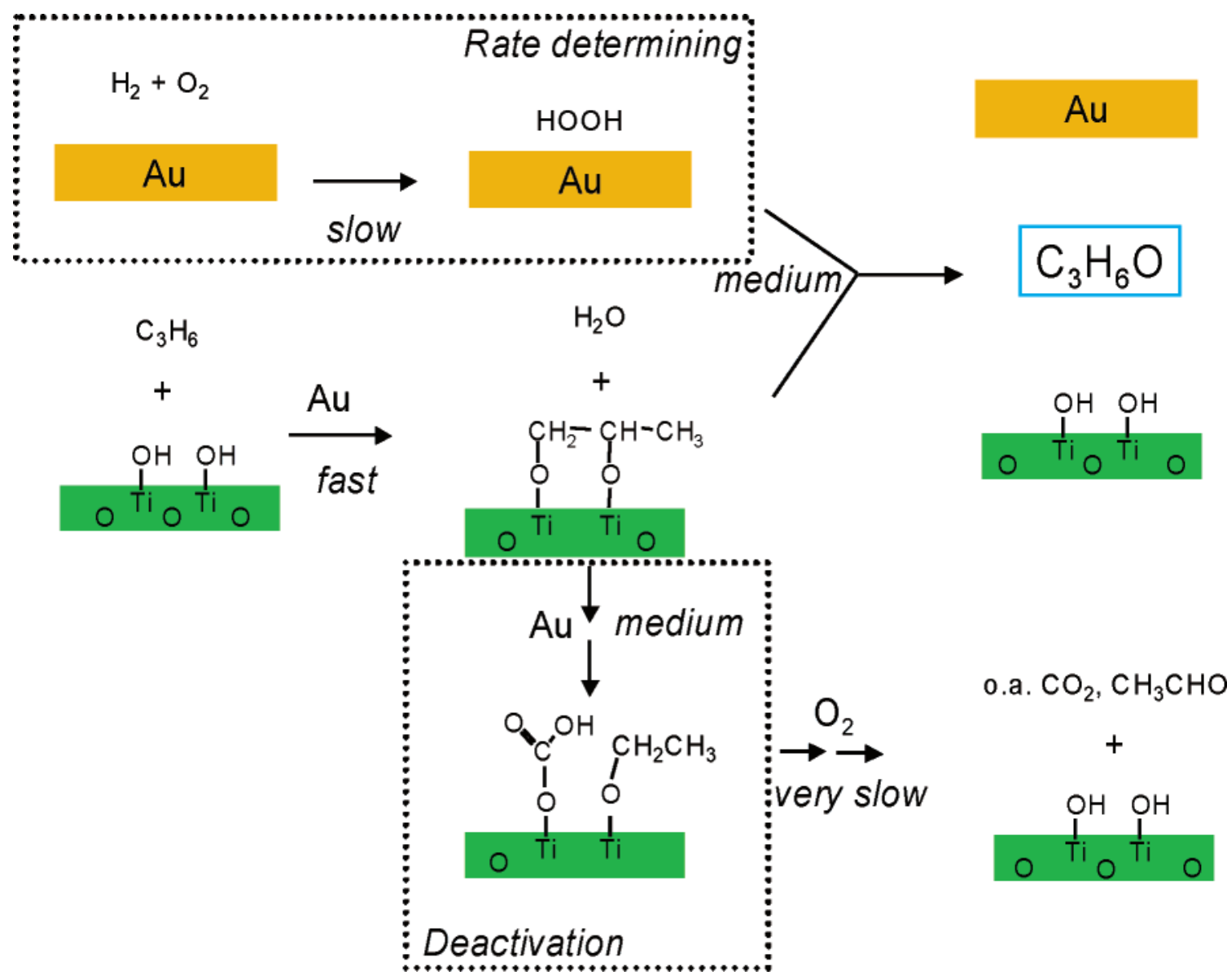

Figure 10. Schematic representation of the model of reaction and deactivation for the propene epoxidation over gold-titania catalysts. ${ }^{86,96}$

recently proposed in the literature. ${ }^{86,96}$ The most important steps that have been proposed are the formation of a peroxide species on the gold (the rate-determining step), a reactive adsorption of propene on titania (catalyzed by the gold nanoparticles) to produce a bidentate propoxy species on titania, and a reactive desorption of this adsorbed species to produce propene oxide as it reacts with the peroxide species on the gold. A very important side reaction that causes the deactivation of the catalyst is the consecutive oxidation of the bidentate propoxy species to carboxylates. ${ }^{86,97}$ The strong adsorption of the propene oxide produced is a key parameter in the catalytic activity. Competitive adsorption of water or alcohols can be used to reduce propene oxide adsorption and slow the deactivation, because less propene oxide is present to be adsorbed on the support. ${ }^{94,98}$

For the gold-titania catalysts, an improved propene oxide yield can be obtained using a support that contains titania in a dispersed manner, typically by using a $\mathrm{Ti}-\mathrm{Si}$ support. ${ }^{87,88,99,100}$ Although the reaction temperature for these catalysts is typically 50-100 K higher than for the gold-titania catalysts, they are considerably more stable (less deactivation) and have a higher propene oxide yield. Modifying the surface of a $\mathrm{Ti}-\mathrm{Si}$ support by sylilation, ${ }^{101,102}$ methylation, ${ }^{102}$ or fluoridation ${ }^{102}$ can improve the performance of the catalyst even further. Propene conversions up to $10 \%$ have been obtained at $90 \%$ selectivity, although the stability of the catalyst at this high conversion level needs to be improved significantly. Improved hydrogen efficiencies have been reported using $\mathrm{CsCl}$ as a promoter. ${ }^{103}$ In patent literature, promoters such as sodium, barium, rubidium, lithium, and magnesium, ${ }^{104}$ as well as potassium, calcium, and lanthanum, ${ }^{102}$ have been added to improve the catalyst. One of the important functions of these promoters is to block acidic sites on the catalyst, which could decompose or oligomerize propene oxide. Also, alloying the gold with small quantities of platinum or palladium has been reported as an excellent way to improve the hydrogen efficiency of this type of catalyst. ${ }^{105,106}$ A catalyst that contains only platinum on a titania-silica support was reported to also have some propene epoxidation activity; ${ }^{106}$ in this case, however, the reported hydrogen efficiency was dramatically low $(<0.1 \%)$.

The improvements that are still being made to the goldtitania catalysts make it likely that, in the future, a gold-titania catalyst for an economically viable process can be found. The main advantage of such a process would be the simplicity of the direct oxidation in a single stage. ${ }^{106}$ The elucidation of the mode of operation of these catalysts will be key to be able to make the needed improvements to the catalyst.

Recently, Hughes et al. ${ }^{107}$ showed that gold catalysts supported on carbon can also be used for selective epoxidation reactions without the need of a sacrificial reductant such as hydrogen. Although this catalyst has not been tested for the propene epoxidation yet and the activity is still low, this work shows that the gold catalysts are still making big steps forward in selective oxidation catalysis.

5.5. Other Processes. To develop a new propene epoxidation process, many alternative approaches have been mentioned in the literature. These include the epoxidation using photochemically activated oxygen, ${ }^{108}$ electrochemical processes, ${ }^{109}$ and biocatalytic systems (enzymes and/or microorganisms). ${ }^{2}$ However, so far, none of these alternative approaches have produced sufficient propene oxide yields to be able to be considered soon as a viable alternative for the existing processes. 


\section{Future Outlook}

Although new processes for the epoxidation are now coming into operation, these should not be considered to be the best solution for the propene epoxidation for the future, nor should the importance of the current processes in operation be discounted. The chlorohydrin process is continuously undergoing small improvements, making it cleaner and cleaner, the chlorine loop is being closed, and the chlorinated side products are being recycled. The hydroperoxide processed will maintain a very important position as long as there is a high demand for their coproducts. Considering the huge market for styrene, especially, the PO-SM process will be in use for a long time. The new processes developed based on a hydrogen peroxide oxidation, produced from hydrogen and oxygen, either by producing it separately or by producing it in situ on a gold catalyst, are very clean processes and, at this moment, have a very promising future; however, the extra energy lost in these processes, in the form of hydrogen being converted to water, make them only a temporary solution. Therefore, the most promising new process for the propene epoxidation will be a direct epoxidation process using only molecular oxygen that still must be developed, comparable to the current ethene epoxidation process.

\section{Conclusions}

With the increasing demand for propene oxide and the limitations of the processes currently in operation, new processes are highly desirable. The new Dow/BASF process that is under construction is a clean process with an unlinked propene oxide production, although the process itself is relatively complex, in that it first produces hydrogen peroxide and thereafter uses that as the oxidant for the epoxidation.

Silver catalysts for the direct epoxidation of propene using oxygen are still not yet viable, although the new silver-calcium carbonate catalyst is a very promising step forward. The gold catalyst systems for the epoxidation are also very promising, yielding very high selectivities under mild conditions; however, the catalyst deactivation, hydrogen efficiency, and conversion still must be improved.

In conclusion, it can be said that the research into new catalysts and processes for the propene epoxidation is not at its end. Improvements are being made continuously and new processes to replace the two existing processes are beginning to be applied.

\section{Acknowledgment}

STW/NWO and NWO/CW are kindly acknowledged for the VIDI and VICI grants that funded the research of T.A.N. and B.M.W. J.-P. Lange is kindly acknowledged for the helpful suggestions for the manuscript. C. van der Spek and M. Versluis are acknowledged for providing the TEM and SEM images.

\section{Literature Cited}

(1) European Chemical Industry Council (CEFIC). Propylene production, consumption and trade balance. Available via the Internet at http:// www.petrochemistry.net, 2005.

(2) Valbert, J. R.; Zajacek, J. G.; Orenbuch, D. I. Propene oxide and glycol. In Encyclopedia of Chemical Processing and Design; Marcel Dekker: New York, 1993; p 88.

(3) Trent, D. L. Propylene oxide. In Kirk-Othmer: Encyclopedia of Chemical Technology; Wiley: New York, 2001. (Online electronic edition.)

(4) Kalich, D.; Wiechern, U.; Linder, J. Propylene Oxide. In Ullman's Encyclopedia of Industrial Chemistry, 5th Edition; Verlag Chemie: Weinheim, Germany, 1993; Vol. A22, p 239.
(5) Pennington, B. T.; Fullington, M. C. (Olin Corporation). Molten salt catalyzed oxidation of alkanes or olefins using lower temperture nitrate salts. U.S. Patent No. 4,943,643, 1990.

(6) Clerici, M. G.; Bellussi, G.; Romano, U. Synthesis of propylene oxide from propylene and hydrogen peroxide catalyzed by titanium silicalite. $J$. Catal. 1991, 129 (1), 159-167.

(7) Tullo, A. Dow, BASF to build propylene oxide. Chem. Eng. News 2004, $82(36), 15$.

(8) Hayashi, T.; Tanaka, K.; Haruta, M. Selective Vapor-Phase Epoxidation of Propylene over $\mathrm{Au} / \mathrm{TiO}_{2}$ Catalysts in the Presence of Oxygen and Hydrogen. J. Catal. 1998, 178 (2), 566-575.

(9) Richey, W. F. Chlorohydrins. In Kirk-Othmer: Encyclopedia of Chemical Technology, 4th Edition; Wiley: New York, 1994; Vol. 6, p 140

(10) Bartolome, E.; Koehler, W.; Stoeckelman, G.; May, A. (BASF Corporation). Continuous manufacture of propylene oxide from propylene chlorohydrine. U.S. Patent No. 3,886,187, 1975.

(11) Morrison, R. T.; Boyd, R. N. Organic Chemistry; Allyn and Bacon: Boston, 1987.

(12) Jorge, E. M. (Dow Chemical Co.). Chlorohydrin process. U.S. Patent No. 6,043,400, 2000.

(13) Cisneros, M. D.; Holbrook, M. T.; Ito, L. N. (Dow Chemical Co.). Hydrodechlorination process and catalyst for use therein. U.S. Patent No. 5,476,984, 1995.

(14) Pell, M.; Korchak, E. I. (Halcon Corporation). Epoxidation using ethylbenzene hydroperoxide with alkali or adsorbent treatment recycle ethylbenzene. U.S. Patent No. 3,439,001, 1969.

(15) Dubner, W. S.; Cochran, R. N. (ARCO Corporation). Propylene oxide-styrene monomer process. U.S. Patent No. 5,210,354, 1993.

(16) Van Der Sluis, J. J. (Shell Corporation). Process for the preparation of styrene and propylene oxide. U.S. Patent No. 6,504,038, 2003.

(17) Kollar, J. (Halcon Corporation). Epoxidation process. U.S. Patent No. $3,351,635,1967$

(18) Marquis, E. T.; Keating, K. P.; Knifton, J. F.; Smith, W. A.; Sanderson, J. R.; Lustri, J. (Texaco Corporation). Olefin epoxidation of olefins in a polar medium. U.S. Patent No. 4,891,437, 1990.

(19) Buijink, J. K. F.; van Vlaanderen, J. J. M.; Crocker, M.; Niele, F. G. M. Propylene epoxidation over titanium-on-silica catalyst-The heart of the SMPO process. Catal. Today 2004, 93-95, 199-204.

(20) Lange, J.-P.; Mesters, C. M. A. M. Mass transport limitations in zeolite catalysts: The dehydration of 1-phenyl-ethanol to styrene. Appl. Catal., A 2001, 210 (1-2), 247-255.

(21) Seo, T.; Tsuji, J. (Sumitomo Corporation). Process for producing propylene oxide. U.S. Patent No. 6,646,139, 2003.

(22) Dever, J. P.; George, K. F.; Hoffman, W. C.; Soo, H. Ethylene Oxide. In Kirk-Othmer: Encyclopedia of Chemical Technology, 4th Edition; Wiley: New York, 1995; Vol. 9, p 915.

(23) Monnier, J. R. The selective epoxidation of nonallylic olefins over supported silver catalysts. Stud. Surf. Sci. Catal. 1997, 110, 135-149.

(24) Lange, J. P. Fuels and chemicals manufactering-Guidelines for understanding and minimizing the production costs. CATTECH 2001, 5 (2), $82-95$.

(25) van Santen, R. A.; de Groot, C. P. M. The mechanism of ethylene epoxidation. J. Catal. 1986, 98, 530-539.

(26) van Santen, R. A.; Kuipers, H. P. C. E. The mechanism of ethylene epoxidation. Adv. Catal. 1987, 35, 265-321.

(27) Geenen, P. V.; Boss, H. J.; Pott, G. T. A study of the vapor-phase epoxidation of propylene and ethylene on silver and silver-gold alloy catalysts. J. Catal. 1987, 77, 499-510.

(28) Carter, E. A.; Goddard, W. A., III. The surface atomic oxyradical mechanism for Ag-catalyzed olefin epoxidation. J. Catal. 1988, 112 (1), $80-92$.

(29) Lambert, R. M.; Williams, F. J.; Cropley, R. L.; Palermo, A. Heterogeneous alkene epoxidation: past, present and future. J. Mol. Catal. A 2005, 228 (1-2), 27-33.

(30) Nijhuis, T. A. Towards a new propene epoxidation processTransient adsorption and kinetics measurements applied in catalysis. Ph.D Thesis, Delft University of Technology, Delft, The Netherlands, 1997.

(31) Roberts, J. T.; Madix, R. J.; Crew, W. W. The Rate-Limiting Step for Olefin Combustion on Silver: Experiment Compared to Theory. J. Catal. 1993, 141, 300-307.

(32) Toreis, N.; Verykios, X. E. The oxidation of ethylene over silverbased alloy catalysts-3. Silver-gold alloys. J. Catal. 1987, 108, 161174.

(33) Zemichael, F. W.; Palermo, A.; Tikhov, M. S.; Lambert, R. M. Propene epoxidation over K-promoted $\mathrm{Ag} / \mathrm{CaCO}_{3}$ catalysts: The effect of metal particle size. Catal. Lett. 2002, 80 (3-4), 93-98.

(34) Pitchai, R.; Kahn, A. P.; Gaffney, A. M. (ARCO Corporation). Vapor phase oxidation of propylene to propylene oxide. U.S. Patent No. $5,625,084,1997$. 
(35) Cooker, B.; Gaffney, A. M.; Jewson, J. D.; Onimus, W. H. (ARCO Corporation). Propylene epoxidation using chloride-containing silver catalysts. U.S. Patent No. 5,780,657, 1998

(36) Bowman, R. G.; Kuperman, A.; Clark, H. W.; Hartwell, G. E.; Meima, G. R. (Dow Chemical Co.). Process for the direct oxidation of olefins to olefin oxides. U.S. Patent No. 6,323,351, 2001.

(37) Wang, R. P.; Guo, X. W.; Wang, X. S.; Hao, J. Q. Gas-phase epoxidation of propylene over Ag/Ti-containing catalysts. Catal. Today 2004, 93-95, 217-222.

(38) Clerici, M. G.; Ingallina, P. (Enichem). Process for producing olefin oxides. U.S. Patent No. 5,221,795, 1993

(39) Venture claims $\mathrm{H}_{2} \mathrm{O}_{2}$ advance. Chem. Eng. News 2005, 83 (11), $14-15$.

(40) Ingallina, P.; Clerici, M. G.; Rossi, L.; Bellussi, G. Catalysis with TS 1: New perspectives for the industrial use of hydrogen peroxide. In Science and Technology in Catalysis 1994, Kodansha: Tokyo, 1995; p 31.

(41) Hess, W. T. Hydrogen Peroxide. In Kirk-Othmer: Encyclopedia of Chemical Technology, 4th Edition; Wiley: New York, 1995; Vol. 13, p 961.

(42) Clerici, M. G.; Ingallina, P. Epoxidation of Lower Olefins with Hydrogen Peroxide and Titanium Silicalite. J. Catal. 1993, 140, 71-83.

(43) Lane, B. S.; Burgess, K. Metal-Catalyzed Epoxidations of Alkenes with Hydrogen Peroxide. Chem. Rev. 2003, 103 (7), 2457-2474.

(44) Tullo, A. BASF, Dow Plan More Propylene Oxide Units. Chem. Eng. News 2005, 83 (44), 7.

(45) Pralus, M.; Lecoq, J. C.; Schirmann, J. P. New wats in the catalytic epoxidation of olefines by hydrogen peroxide. In Fundamental Research in Homogeneous Catalysis; Plenum: New York, 1979; p 327.

(46) Sheldon, R. A.; Kochi, J. K. Metal catalysis in peroxide reactions. In Metal Catalyzed Oxidations of Organic Compounds, Academic Press: New York, 1981; p 33

(47) Ishihara, T.; Ohura, Y.; Yoshida, S.; Hata, Y.; Nishiguchi, H.; Takita, Y. Synthesis of hydrogen peroxide by direct oxidation of $\mathrm{H}_{2}$ with $\mathrm{O}_{2}$ on $\mathrm{Au} / \mathrm{SiO}_{2}$ catalyst. Appl. Catal., A 2005, 291 (1-2), 215.

(48) Landon, P.; Collier, P. J.; Papworth, A. J.; Kiely, C. J.; Hutchings, G. J. Direct formation of hydrogen peroxide from $\mathrm{H}_{2} / \mathrm{O}_{2}$ using a gold catalyst. Chem. Commun. 2002, (18), 2058-2059.

(49) Jenzer, G.; Mallat, T.; Maciejewski, M.; Eigenmann, F.; Baiker, A. Continuous epoxidation of propylene with oxygen and hydrogen on a Pd-Pt/TS-1 catalyst. Appl. Catal., A 2001, 208 (1-2), 125-133.

(50) Yong, Y. S.; Cant, N. W. Ethylene oxidation over silver catalysts: A study of mechanism using nitrous oxide and isotopically labeled oxygen. J. Catal. 1990, 122, 22-33.

(51) Ananieva, E.; Reitzmann, A. Direct gas-phase epoxidation of propene with nitrous oxide over modified silica supported $\mathrm{FeO}_{x}$ catalysts. Chem. Eng. Sci. 2004, 59 (22-23), 5509-5517.

(52) Iwasawa, Y.; Nakamura, T.; Takamatsu, K.; Ogasawara, S. Study of the partial oxidation of propene by $\mathrm{O}_{2}$ and $\mathrm{N}_{2} \mathrm{O}$ over fixed Mo catalysts. Essential factors for catalysis and reaction mechanisms. J. Chem. Soc., Faraday Trans., 1 1980, 79, 939-951.

(53) Panov, G. I.; Sheveleva, G. A.; Kharitonov, A. S.; Romannikov, V. N.; Vostrikova, L. A. Oxidation of Benzene to Phenol by Nitrous-Oxide over Fe-Zsm-5 Zeolites. Appl. Catal., A 1992, 82 (1), 31-36.

(54) Parmon, V. N.; Panov, G. I.; Uriarte, A.; Noskov, A. S. Nitrous oxide in oxidation chemistry and catalysis: application and production. Catal. Today 2005, 100 (1-2), 115-131.

(55) Wang, X.; Zhang, Q.; Guo, Q.; Lou, Y.; Yang, L.; Wang, Y. Ironcatalyzed propylene epoxidation by nitrous oxide: dramatic shift of allylic oxidation to epoxidation by the modification with alkali metal salts. Chem. Commun. 2004, 1396-1397.

(56) Davis, D. D.; Kemp, D. R., Adipic Acid. In Kirk-Othmer: Encyclopedia of Chemical Technology, 4th Edition; Wiley: New York, 1992; Vol. 1, p 466

(57) Lange, J. P. Economics of alkane conversion. In Sustainable Strategies for the Upgrading of Natural Gas: Fundamentals, Challenges, and Opportunities; Derouane, E. G., Parmon, V., Lemos, F., Ribeiro, F. R., Eds.; Kluwer: Dordrecht, The Netherlands, 2005; pp 51-83.

(58) Pennington, B. T. (Olin Corporation). Alkylene oxides production using molten nitrate salt catalyst and a cocatalyst. U.S. Patent No. 4,883,889, 1989.

(59) Pennington, B. T. (Olin Corporation). Alkylene oxides production using molten nitrate salt catalysts. European Patent No. EP 0268870, 1988

(60) Pennington, B. T. (Olin Corporation). Alkylene oxides production from alkanes or alkylaromatics using molten nitrate salt catalyst. U.S. Patent No. 4,885,374, 1988.

(61) Meyer, J. L.; Pennington, B. T. (Olin Corporation). Alkylene oxide production using vapor phase oxidation of an alkane or olefin in molten salt and recirculation of aldehyde byproducts. U.S. Patent No. 4,992,567, 1991.
(62) Nijhuis, T. A.; Musch, S.; Makkee, M.; Moulijn, J. A. The direct epoxidation of propene by molten salts. Appl. Catal., A 2000, 196 (2), $217-$ 224

(63) Stark, M. S.; Waddington, D. J. Oxidation of Propene in the GasPhase. Int. J. Chem. Kinet. 1995, 27 (2), 123-151.

(64) Dagaut, P.; Cathonnet, M.; Boettner, J. C. A Kinetic Modeling Study of Propene Oxidation in JSR and Flame. Combust. Sci. Technol. 1992, 83 (4-6), 167-185

(65) Wilk, R. D.; Cernansky, N. P.; Pitz, W. J.; Westbrook, C. K. Propene Oxidation At Low And Intermediate Temperatures-A Detailed Chemical Kinetic-Study. Combust. Flame 1989, 77 (2), 145-170.

(66) Fullington, M. C.; Pennington, B. T. (Olin Corporation). Direct oxidation of propylene to propylene oxide. Patent Application No. WO 92/ 09588, 1992.

(67) Jorgensen, K. A. Transition-metal-catalyzed epoxidations. Chem. Rev. 1989, 89, 431-458.

(68) Sheldon, R. A. Synthetic and mechanistic aspects of metal-catalysed epoxidations with hydroperoxides. J. Mol. Catal. 1980, 7, 107-126.

(69) Haber, J.; Mlodnicka, T.; Poltowicz, J. Metal-dependent reactivity of some metalloporphyrins in oxidation with dioxygen. J. Mol. Catal. 1989, $54,451-461$.

(70) Baer, H. G.; Ralek, M. Direct liquid-phase oxidation of propene to propene oxide. Appl. Catal. 1983, 7, 11-20.

(71) Jacobsen, S. E. (Halcon Corporation). Process for production of olefin oxides and ketones. U.S. Patent No. 4,483,996, 1984.

(72) Haruta, M.; Yamada, N.; Kobayashi, T.; Iijima, S. Gold catalysts prepared by coprecipitation for low-temperature oxidation of hydrogen and of carbon monoxide. J. Catal. 1989, 115 (2), 301-309.

(73) Chen, M. S.; Goodman, D. W. The structure of catalytically active gold on titania. Science 2004, 306 (5694), 252-255.

(74) Nijhuis, T. A.; Visser, T.; Weckhuysen, B. M. The Role of Gold in Gold-Titania Epoxidation Catalysts. Angew. Chem., Int. Ed. 2005, 44 (7), 1115-1118.

(75) Campbell, C. T. The active site in nanoparticle gold catalysis. Science 2004, 306 (5694), 234-235.

(76) Chretien, S.; Gordon, M. S.; Metiu, H. Binding of propene on small gold clusters and on $\mathrm{Au}(111)$ : Simple rules for binding sites and relative binding energies. J. Chem. Phys. 2004, 121 (8), 3756-3766.

(77) Costello, C. K.; Guzman, J.; Yang, J. H.; Wang, Y. M.; Kung, M. C.; Gates, B. C.; Kung, H. H. Activation of $\mathrm{Au} / \gamma-\mathrm{Al}_{2} \mathrm{O}_{3}$ Catalysts for $\mathrm{CO}$ Oxidation: Characterization by X-ray Absorption Near Edge Structure and Temperature Programmed Reduction. J. Phys. Chem. B 2004, 108 (33), 12529-12536.

(78) Arrii, S.; Morfin, F.; Renouprez, A. J.; Rousset, J. L. Oxidation of $\mathrm{CO}$ on gold supported catalysts prepared by laser vaporization: Direct evidence of support contribution. J. Am. Chem. Soc. 2004, 126 (4), 11991205.

(79) Kimble, M. L.; Castleman, A. W.; Mitric, R.; Burgel, C.; BonacicKoutecky, V. Reactivity of atomic gold anions toward oxygen and the oxidation of CO: Experiment and theory. J. Am. Chem. Soc. 2004, 126 (8), 2526-2535.

(80) Guzman, J.; Gates, B. C. Catalysis by supported gold: Correlation between catalytic activity for CO oxidation and oxidation states of gold. $J$. Am. Chem. Soc. 2004, 126 (9), 2672-2673.

(81) Lopez, N.; Janssens, T. V. W.; Clausen, B. S.; Xu, Y.; Mavrikakis, M.; Bligaard, T.; Norskov, J. K. On the origin of the catalytic activity of gold nanoparticles for low-temperature CO oxidation. J. Catal. 2004, 223 (1), 232-235.

(82) Meier, D. C.; Goodman, D. W. The influence of metal cluster size on adsorption energies: $\mathrm{CO}$ adsorbed on Au clusters supported on $\mathrm{TiO}_{2}$. J Am. Chem. Soc. 2004, 126 (6), 1892-1899.

(83) Zanella, R.; Louis, C.; Giorgio, S.; Touroude, R. Crotonaldehyde hydrogenation by gold supported on $\mathrm{TiO}_{2}$ : structure sensitivity and mechanism. J. Catal. 2004, 223 (2), 328-339.

(84) Schumacher, B.; Denkwitz, Y.; Plzak, V.; Kinne, M.; Behm, R. J. Kinetics, mechanism, and the influence of $\mathrm{H}_{2}$ on the $\mathrm{CO}$ oxidation reaction on a $\mathrm{Au} / \mathrm{TiO}_{2}$ catalyst. J. Catal. 2004, 224 (2), 449-462.

(85) Date, M.; Okumura, M.; Tsubota, S.; Haruta, M. Vital role of moisture in the catalytic activity of supported gold nanoparticles. Angew. Chem., Int. Ed. 2004, 43 (16), 2129-2132.

(86) Nijhuis, T. A.; Visser, T.; Weckhuysen, B. M. A mechanistic study into the direct epoxidation of propene over gold-titania catalysts. J. Phys. Chem. B 2005, 109, 19309-19319.

(87) Stangland, E. E.; Stavens, K. B.; Andres, R. P.; Delgass, W. N. Characterization of Gold-Titania Catalysts via Oxidation of Propylene to Propylene Oxide. J. Catal. 2000, 191 (2), 332-347.

(88) Nijhuis, T. A.; Huizinga, B. J.; Makkee, M.; Moulijn, J. A. Direct epoxidation of propene using gold dispersed on TS-1 and other titaniumcontaining supports. Ind. Eng. Chem. Res. 1999, 38 (3), 884-891. 
(89) Sivadinarayana, C.; Choudhary, T. V.; Daemen, L. L.; Eckert, J.; Goodman, D. W. The nature of the surface species formed on $\mathrm{Au} / \mathrm{TiO}_{2}$ during the reaction of $\mathrm{H}_{2}$ and $\mathrm{O}_{2}$ : An inelastic neutron scattering study. $J$. Am. Chem. Soc. 2004, 126 (1), 38-39.

(90) Barton, D. G.; Podkolzin, S. G. Kinetic study of a direct water synthesis over silica-supported gold nanoparticles. J. Phys. Chem. B 2005, 109 (6), 2262-2274.

(91) Wells, D. H.; Delgass, W. N.; Thomson, K. T. Formation of hydrogen peroxide from $\mathrm{H}_{2}$ and $\mathrm{O}_{2}$ over a neutral gold trimer: A DFT study. J. Catal. 2004, 225 (1), 69-77.

(92) Olivera, P. P.; Patrito, E. M.; Sellers, H. Hydrogen-Peroxide Synthesis Over Metallic Catalysts. Surf. Sci. 1994, 313 (1-2), 25-40.

(93) Qi, C.; Okumura, M.; Akita, T.; Haruta, M. Vapor-phase epoxidation of propylene using $\mathrm{H}_{2} / \mathrm{O}_{2}$ mixture over gold catalysts supported on nonporous and mesoporous titania-silica: effect of preparation conditions and pretreatments prior to reaction. Appl. Catal., A 2004, 263 (1), 19-26.

(94) Zwijnenburg, A.; Makkee, M.; Moulijn, J. A. Increasing the low propene epoxidation product yield of gold/titania-based catalysts. Appl. Catal., A 2004, 270 (1-2), 49-56.

(95) Haruta, M.; Date, M. Advances in the catalysis of Au nanoparticles. Appl. Catal., A 2001, 222 (1-2), 427-437.

(96) Nijhuis, T. A.; Gardner, T. Q.; Weckhuysen, B. M. Modeling of kinetics and deactivation in the direct epoxidation of propene over goldtitania catalysts. J. Catal. 2005, 236, 153-163.

(97) Mul, G.; Zwijnenburg, A.; van der Linden, B.; Makkee, M.; Moulijn, J. A. Stability and selectivity of $\mathrm{Au} / \mathrm{TiO}_{2}$ and $\mathrm{Au} / \mathrm{TiO}_{2} / \mathrm{SiO}_{2}$ catalysts in propene epoxidation: An in situ FT-IR study. J. Catal. 2001 201 (1), 128-137.

(98) Nijhuis, T. A.; Weckhuysen, B. M. The role of water in the epoxidation over gold-titania catalysts. Chem. Commun. 2005, 48, 60026004.

(99) Yap, N.; Andres, R. P.; Delgass, W. N. Reactivity and stability of $\mathrm{Au}$ in and on TS-1 for epoxidation of propylene with $\mathrm{H}_{2}$ and $\mathrm{O}_{2}$. J. Catal. 2004, 226 (1), 156-170.

(100) Sinha, A. K.; Seelan, S.; Akita, T.; Tsubota, S.; Haruta, M. Vapor phase propylene epoxidation over $\mathrm{Au} / \mathrm{Ti}-\mathrm{MCM}-41$ catalysts prepared by different Ti incorporation modes. Appl. Catal., A 2003, 240 (1-2), 243252
(101) Sinha, A. K.; Seelan, S.; Tsubota, S.; Haruta, M. A threedimensional mesoporous titanosilicate support for gold nanoparticles: Vapor-phase epoxidation of propene with high conversion. Angew. Chem. Int. Ed. 2004, 43 (12), 1546-1548.

(102) Weisbeck, M.; Schild, C.; Wegener, G.; Wiessmeier, G. (BASF Corporation). Surface-modified mixed oxides containing precious metal and titanium, for the selective oxidation of hydrocarbons. U.S. Patent No. 6,734,133, 2004.

(103) Uphade, B. S.; Okumura, M.; Tsubota, S.; Haruta, M. Effect of physical mixing of $\mathrm{CsCl}$ with $\mathrm{Au} / \mathrm{Ti}-\mathrm{MCM}-41$ on the gas-phase epoxidation of propene using $\mathrm{H}_{2}$ and $\mathrm{O}_{2}$ : Drastic depression of $\mathrm{H}_{2}$ consumption. Appl. Catal., A 2000, 190 (1-2), 43-50.

(104) Kuperman, A.; Bowman, R. G.; Hartwell, G. E.; Schoeman, B. J.; Tuinstra, H. E.; Meima, G. R. (Dow Chemical Co.). Process for the hydro-oxidation of olefins to olefin oxides using oxidized gold catalyst. U.S. Patent No. 6,255,499, 2001.

(105) Makkee, M.; Zwijnenburg, A.; Moulijn, J. A. (Huntsman). Gasphase process and catalyst for the preparation of propylene oxide. Patent Application No. WO 03/062196, 2003.

(106) Zwijnenburg, A. Propene epoxidation over gold/titania and silver catalysts. Ph.D. Thesis, Delft University of Technology, Delft, The Netherlands, 2002.

(107) Hughes, M. D.; Xu, Y.-J.; Jenkins, P.; McMorn, P.; Landon, P.; Enache, D. I.; Carley, A. F.; Attard, G. A.; Hutchings, G. J.; King, F.; Stitt, E. H.; Johnston, P.; Griffin, K.; Kiely, C. J. Tunable gold catalysts for selective hydrocarbon oxidation under mild conditions. Nature $\mathbf{2 0 0 5}$, 437, 1132-1135.

(108) Ward, M. D.; Bradzil, J. F.; Grasselli, R. K. (Sohio Corporation). U.S. Patent No. 4,571,290, 1986.

(109) Trent, D. L. Propylene oxide. In Kirk-Othmer: Encyclopedia of Chemical Technology, 4th Edition; 1996; Vol. 20, p 271.

Received for review November 24, 2005

Revised manuscript received March 9, 2006 Accepted March 13, 2006 